\title{
Observed HIRS and MODIS High-Cloud Frequencies in the 2000s
}

\author{
Richard A. Frey AND W. PAul MenZel \\ Cooperative Institute for Meteorological Satellite Studies, Space Science and Engineering Center, \\ University of Wisconsin-Madison, Madison, Wisconsin
}

(Manuscript received 8 March 2019, in final form 18 September 2019)

\begin{abstract}
This paper compares the cloud parameter data records derived from High Resolution Infrared Radiation Sounder (HIRS) and Moderate Resolution Imaging Spectroradiometer (MODIS) measurements from the years 2003 through 2013. Cloud-top pressure (CTP) and effective emissivity ( $\varepsilon f$; cloud emissivity multiplied by cloud fraction) are derived using the 15- $\mu \mathrm{m}$ spectral bands in the $\mathrm{CO}_{2}$ absorption band and implementing the $\mathrm{CO}_{2}$-slicing technique; the approach is robust for high semitransparent clouds but weak for low clouds with little thermal contrast from clear-sky radiances. The high-cloud ( $\mathrm{HiCld}$; with CTP less than $440 \mathrm{hPa}$ ) seasonal cycles of HIRS and MODIS observations are found to be in sync, but the HIRS frequency of detection is about $10 \%$ higher than that of MODIS (which is attributed to a lower threshold for cloud detection in the HIRS $\mathrm{CO}_{2}$ bands). Differences are largest during nighttime and at the beginning of the time series (2003-06). Both show Northern Hemisphere (NH) and Southern Hemisphere (SH) seasonal HiClds are out of phase and both agree within $2 \%$ on $\mathrm{NH}-\mathrm{SH}$ HiCld differences. During the summer, maximum HiCld frequency averages $5 \%$ more in the $\mathrm{NH}$.
\end{abstract}

\section{Introduction}

Clouds have a direct impact on Earth's energy balance. Cloud type and height determine the strength and sign of that impact (warming or cooling at the top of the atmosphere). It has been shown that lower clouds and high thick clouds generally cool the planet, while high transmissive clouds generally have a warming effect (Hartmann et al. 1992; Chen et al. 2000). Long-term trends in cloud cover would obviously play an important role in the evolution of our planet's energy budget (Zhou et al. 2016).

Several groups have constructed more than 35-yr records using similar or identical instruments that have launched on multiple satellites. One record, the International Satellite Cloud Climatology Project (ISCCP), primarily merges visible reflectances and longwave infrared window radiances from geostationary and polarorbiting satellites (Schiffer and Rossow 1983; Rossow and Schiffer 1991). While this has provided information about clouds and their variation from diurnal to decadal time scales, some issues result from the geostationary

\footnotetext{
Corresponding author: Richard A. Frey, richard.frey@ssec.wisc. edu
}

perspective (e.g., Evan et al. 2007). Another climate data record of cloud products has been produced using the polar-orbiting Advanced Very High Resolution Radiometer (AVHRR). The Pathfinder AtmospheresExtended (PATMOS-x), version 5.3, spans from 1979 to the present with daily, global coverage provided by 14 National Oceanic and Atmospheric Administration (NOAA) and 2 MetOp satellites (Foster and Heidinger 2013; Heidinger et al. 2014). A complementary cloud record used the High Resolution Infrared Radiation Sounder (HIRS) on board NOAA and MetOp satellites (e.g., Wylie and Menzel 1999; Wylie et al. 2005). More recently, the HIRS data record has been reprocessed to provide nearly four decades of data from 1980 to 2015 (Menzel et al. 2016). This dataset uses infrared channel $\mathrm{CO}_{2}$-slicing methods coupled with auxiliary collocated cloud information from the accompanying PATMOS-x cloud dataset (Nagle and Holz 2009).

However, studies of cloud trends using long-term satellite records are inconclusive. Using HIRS observations, Wylie et al. (2005) reported a slight positive trend in high clouds from 1979 to 2001 in the tropics and Northern Hemisphere; however, the same study found a slight decrease in the ISCCP time series. Evan et al. (2007) 
suggested that decreasing trends in the ISCCP data are due to satellite viewing geometry artifacts and not to physical changes in the atmosphere. Relying on landbased surface observations, Eastman and Warren (2013) reported a small decrease in high clouds from 1971 to 2009 .

In this paper, we compare the frequency of high-cloud detection in HIRS versus Aqua Moderate Resolution Imaging Spectroradiometer (MODIS) measurements from 2003 to 2013. The instruments share the same $\mathrm{CO}_{2}$-sensitive absorption bands and their radiance measurements were processed using very similar $\left(\mathrm{CO}_{2}\right.$ slicing) cloud-top pressure (CTP) algorithms. Part of this effort is to verify the HIRS CTPs and highcloud frequencies (HCFs) by using the carefully tuned MODIS cloud detection and $\mathrm{CO}_{2}$-slicing algorithms as a benchmark. Even though HIRS instruments varied slightly between different platforms over the years, there will be added confidence in the entire record of HIRS CTPs (1980-present) if spatial and temporal patterns match those of MODIS. More confidence may be accorded the MODIS results too, if the records show similar behavior through the years.

\section{Instruments, data, and algorithms}

Operational HIRS have flown on NOAA platforms beginning with TIROS-N, followed by NOAA-6 through NOAA-19. The MetOp-A and MetOp-B platforms operated by the European Organization for the Exploitation of Meteorological Satellites (EUMETSAT) also carry a HIRS on board. The AVHRR has accompanied the HIRS on all of these satellites. HIRS and AVHRR have been making measurements since 1978. MODIS have been included the on the morning (Terra) and afternoon (Aqua) platforms of the NASA Earth Observing System. The MODIS data record extends back to 2000.

The HIRS sensor was designed to take measurements in 19 infrared (IR) channels and one solar channel. Small improvements in the sensor over the years have resulted in a smaller field of view (FOV), spectral adjustments, and a better signal to noise in the radiance measurements. The HIRS nominal spatial resolutions at nadir changed from contiguous $20 \mathrm{~km}$ on HIRS $/ 2$ (NOAA-6 through $N O A A-14), 18 \mathrm{~km}$ on HIRS/3 (NOAA-15 through $N O A A-17$ ), to sampled $10 \mathrm{~km}$ on HIRS/4 (NOAA-18 and NOAA-19, MetOp-A and MetOp-B). The HIRS spectral response functions (SRFs) determined prelaunch have been adjusted after comparison of the radiance measurements with the high-spectral-resolution Infrared Atmospheric Sounding Interferometer (IASI) on MetOp-A (Chen et al. 2013).
The MODIS senses 36 spectral bands from the NASA Terra and Aqua platforms (Salomonson et al. 1989). Sixteen of those bands range in the infrared from 3.6 to $14.4 \mu \mathrm{m}$ with SRFs designed to mimic those on HIRS. In the sixth collection and processing of the MODIS data [Collection 6 (C6)], several calibration and cloud product retrieval improvements were implemented. The cloud-top parameters (height, pressure, temperature, and IR phase) are provided at 1- and 5-km spatial resolutions.

The cloud-top pressure/height algorithm refined for MODIS C6 was also used to establish the cloud records from the HIRS data. The algorithm is described in detail in the literature [for the MODIS implementation, see Menzel et al. (2008) and Baum et al. (2012); for the HIRS implementation, see Menzel et al. (2016)].

Cloud detection is accomplished as follows. AVHRR Global Area Coverage (GAC) pixels $(1.1 \mathrm{~km} \times 4.4 \mathrm{~km}$ spatial resolution at nadir) are collocated within a HIRS FOV to indicate the presence of cloud using the Clouds from AVHRR-Extended (CLAVR-x) algorithm (Heidinger et al. 2012). GAC data are obtained by sampling the AVHRR full-resolution 1.1-km data so that for a given scan line the first four pixels out of every five are averaged, and only every third scan line is processed. The MODIS cloud mask at $1-\mathrm{km}$ resolution (Ackerman et al. 1998) is used to determine the cloudiness within $5 \mathrm{~km} \times 5 \mathrm{~km}$ fields of regard (FORs). When $15 \%$ or more of a HIRS FOV or a MODIS FOR is determined to be cloud covered, a CTP retrieval is attempted (the cloudy 1-km MODIS radiances within the FOR are averaged for the retrieval).

$\mathrm{CO}_{2}$ slicing is used when calculated clear minus observed cloudy radiance differences in the $\mathrm{CO}_{2}$ spectral bands centered at 14.2, 13.9, 13.6, and $13.3 \mu \mathrm{m}$ are greater than a threshold value $\left(0.5 \mathrm{~mW} \mathrm{~m}^{-2} \mathrm{ster}^{-1} \mathrm{~cm}^{-1}\right.$ for HIRS and ranging from 1.0 to $4.0 \mathrm{~mW} \mathrm{~m}^{-2} \mathrm{ster}^{-1} \mathrm{~cm}^{-1}$ for Aqua MODIS). The HIRS threshold value is well above the noise throughout HIRS instrument history; the higher MODIS threshold value is necessary because 10 different detectors are utilized when processing MODIS FORs. Clear-sky radiances are calculated using model atmospheric profile data [Climate Forecast System Reanalysis (CFSR) for HIRS and Global Data Assimilation System (GDAS) for MODIS]. CFSR (Kalnay et al. 1996) and GDAS (Kanamitsu et al. 1991) mean temperature profiles for all levels above $400 \mathrm{hPa}$ agree to better than $2^{\circ} \mathrm{C}$ so that model-induced differences in the calculation of $\mathrm{CO}_{2}$ slicing CTPs have been found to be less than $15 \mathrm{hPa}$ (Menzel et al. 1992). In cases where these thresholds are not met for at least two adjacent $\mathrm{CO}_{2}$ spectral bands, the default infrared window (IRW) determination of an 


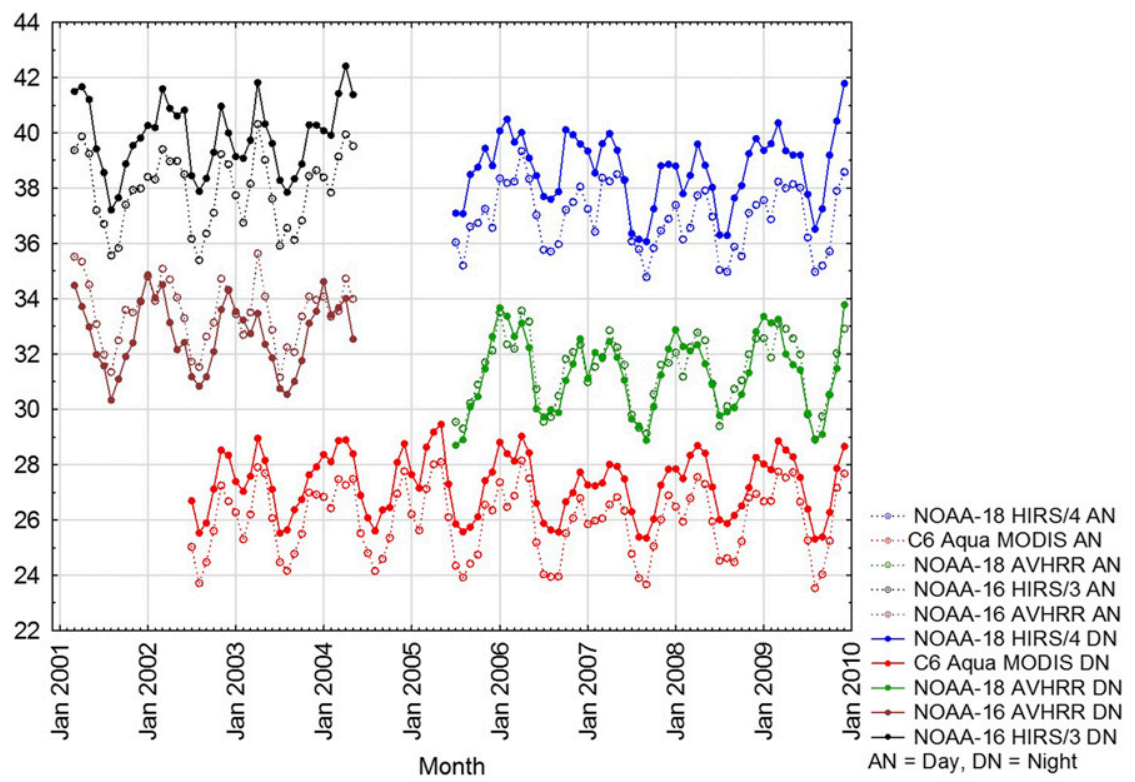

FIG. 1. Ascending-node (dotted) and descending-node (solid) Aqua MODIS, NOAA-16 HIRS, $N O A A-18$ HIRS, NOAA-16 AVHRR GAC, and $N O A A-18$ AVHRR GAC high-cloud detection frequencies from January 2001 to January 2010.

(assumed to be) opaque CTP is reported. An infrared-based cloud phase determination is used to confine the $\mathrm{CO}_{2}$-slicing algorithm to ice clouds, deferring to the IRW determination for water clouds and those ice clouds failing the $\mathrm{CO}_{2}$ radiance threshold tests (Baum et al. 2012).

High-cloud (HiCld) detection is defined to be clouds with CTP less than $440 \mathrm{hPa}$. $\mathrm{CO}_{2}$-slicing determinations of CTPs have been found to be within $50 \mathrm{hPa}$. When the HiCld threshold is changed to $415 \mathrm{hPa}, \mathrm{HCF}$ from $60^{\circ} \mathrm{N}$ to $60^{\circ} \mathrm{S}$ was found to decrease by $2.5 \%$ for January and July of 2005; when changed to $465 \mathrm{hPa}$, an increase of less than $0.9 \%$ occurred. Therefore, the global average HiCld detection frequency is believed to be within $2.5 \%$ for any month.

\section{Observations of high clouds}

A comparison of MODIS (Baum et al. 2012), HIRS (Menzel et al. 2016), and AVHRR (Heidinger et al. 2014) high-cloud detection frequencies by day (ascending node) and night (descending node) for 2001-10 is shown in Fig. 1. Both MODIS and HIRS record $1 \%-2 \%$ additional high clouds at night than in the day, while AVHRR shows little change. Seasonal cycles match well but HIRS finds more high clouds than AVHRR and MODIS. Differences are due to the processing FOV size ( $5 \mathrm{~km}$ for MODIS, $18 \mathrm{~km}$ for HIRS/3, $10 \mathrm{~km}$ for HIRS/4, and $4 \mathrm{~km}$ for AVHRR GAC), available spectral bands (HIRS and MODIS have $\mathrm{CO}_{2}$ sensitive bands supplementing the IR windows, but AVHRR does not), and cloud detection thresholds (HIRS shares the AVHRR cloud mask for detection but uses $\mathrm{CO}_{2}$ bands to help in classifying high clouds; MODIS has a very sensitive cloud mask but uses the $\mathrm{CO}_{2}$ bands more sparingly to classify high clouds). Smaller FOVs will find fewer clouds (Smith et al. 1996; Wylie and Wang 1997), absence of $\mathrm{CO}_{2}$ bands will cause thin high clouds to be misclassified as low opaque cloud, and lower cloud detection thresholds in the $\mathrm{CO}_{2}$ bands will enable more high thin cloud identification (Kolat 2010). The MODIS processing FOR consists of $5 \times 5$ individual $1 \mathrm{~km}$ FOVs, which results in higher cloud detection thresholds to accommodate differing detector sensitivities. Overall HIRS, using the $\mathrm{CO}_{2}$ sensitive bands to discriminate thin high cirrus more often, sees roughly $10 \%$ more high clouds than MODIS and 5\% more than AVHRR GAC.

Orbit drift causes the equator crossing times (polarorbiting satellites are intended to cross the equator traveling from south to north at the same local solar time each day) to occur later in the day in the HIRS observations and this in turn alters HCFs during daytime due to changes in diurnal surface heating. To mitigate this somewhat, we limit the HIRS data in this analysis to the operational time periods wherein the drift was confined to be less than one hour. Aqua MODIS equator crossing time is fixed at $1330 \mathrm{LT}$, while those for HIRS on NOAA-16, $N O A A-18$, and NOAA-19 range from 1400 to $1500 \mathrm{LT}$ during their operational lifetimes. 
(a)

$$
\text { Hovmoller Diagram of MODIS DN (Night) High Cloud Frequency (\%) }
$$

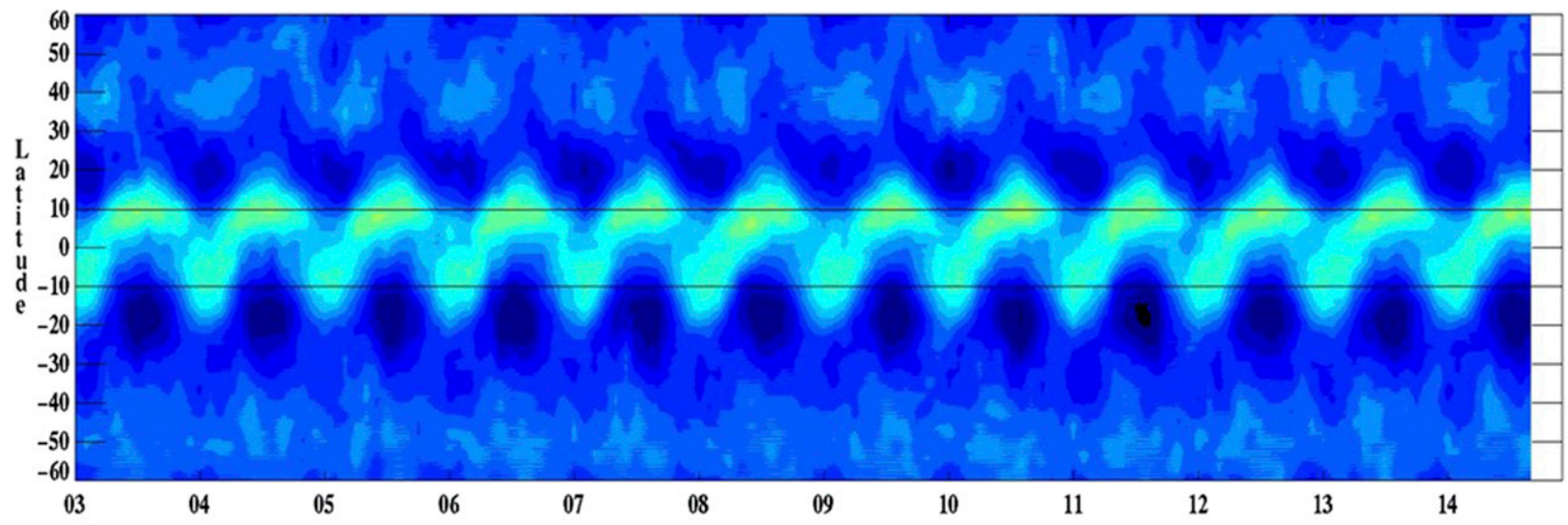

Hovmoller Diagram of HIRS Night High Cloud Frequency (\%)
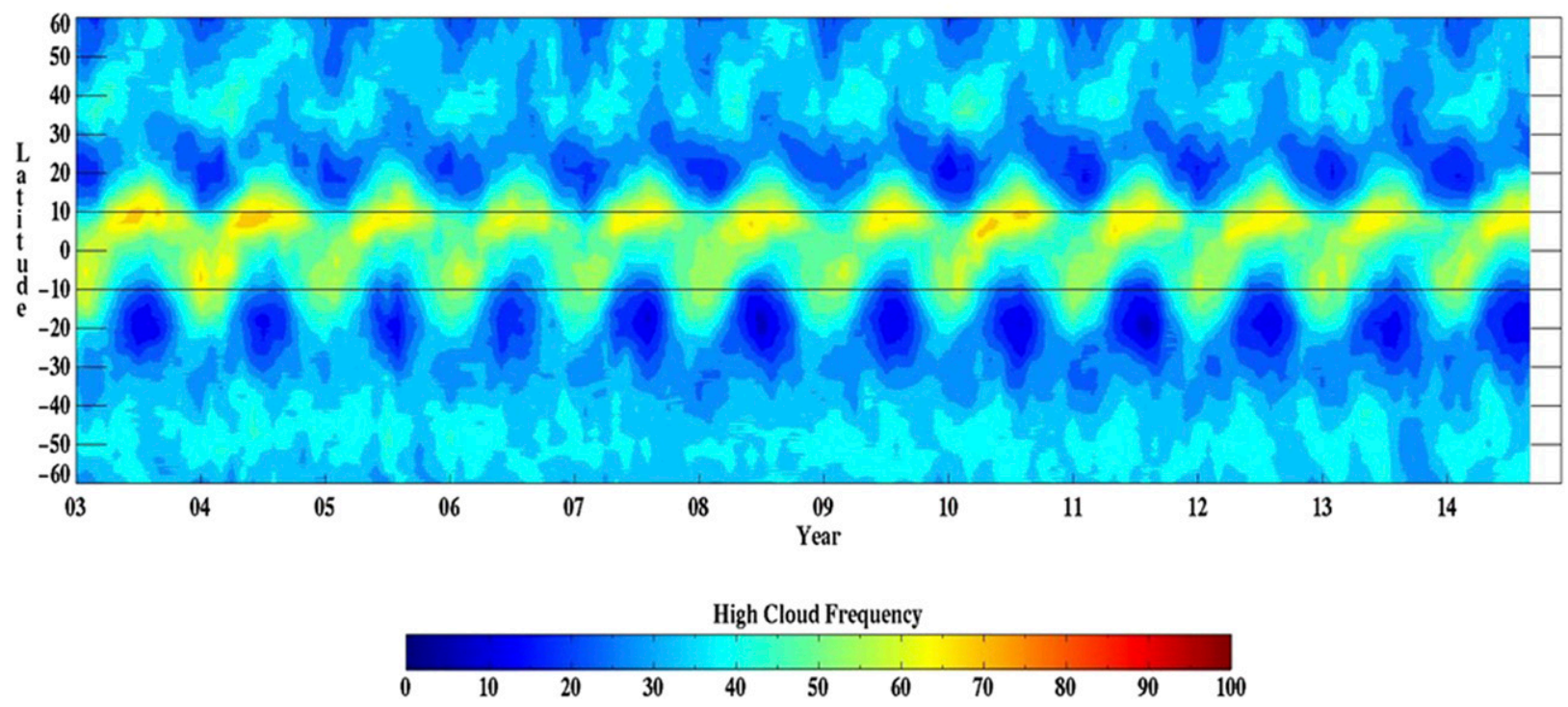

FIG. 2. (a) Hovmöller plot of nighttime high-cloud detection in 2003-14 for (top) Aqua MODIS and (bottom) NOAA-16, NOAA-18, and NOAA-19 HIRS. (b) Hovmöller plot of afternoon high-cloud detection in 2003-14 for (top) Aqua MODIS and (bottom) $N O A A-16, N O A A-18$, and NOAA-19 HIRS. (c) Hovmöller plot of HIRS minus MODIS HCFs in 2003-14 for (top) night and (bottom) afternoon.

Hovmöller plots in Fig. 2a indicate similar seasonal patterns between MODIS (top) and HIRS (bottom) HCFs at night but as noted above there are differences in their numbers. The relative absence of high clouds midyear between $10^{\circ}$ and $30^{\circ} \mathrm{S}$ is noteworthy and again 6 months later between $10^{\circ}$ and $30^{\circ} \mathrm{N}$. Also note the sinusoidal pattern of HCFs in the NH midlatitudes that is not seen in the $\mathrm{SH}$, presumably due to more land surface in the $\mathrm{NH}$ that leads to more convection during summer. This pattern has been seen very clearly in time series plots of clear and cloudy observed HIRS brightness temperatures (Wylie and Menzel 1999) and in HCFs using an earlier $\mathrm{CO}_{2}$-slicing algorithm (Wylie et al.
2005). Figure $2 b$ shows the same data but for afternoon orbits. Again, seasonal patterns are quite similar but HIRS shows mostly higher HCFs. Figure 2c shows HIRS minus MODIS HCF differences for night (top) and afternoon (bottom). Nighttime differences are almost exclusively positive with larger values clustered near the beginning of the study period where the HIRS data is taken from NOAA-16. Afternoon differences are mostly smaller than night, excepting (for the most part) the deep tropics and SH midlatitudes. Interestingly, there are some regions in the NH where HIRS minus MODIS HCF is negative. We do not currently have an explanation for this phenomenon. Note that there seem 
(b)

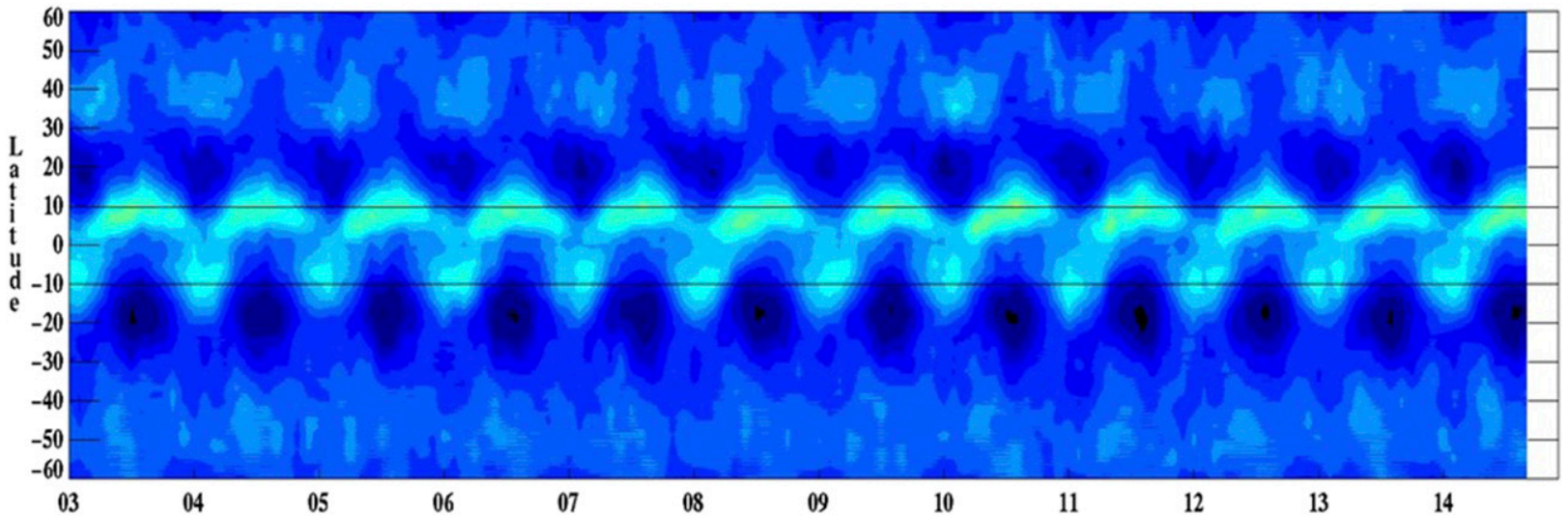

Hovmoller Diagram of HIRS Afternoon High Cloud Frequency (\%)
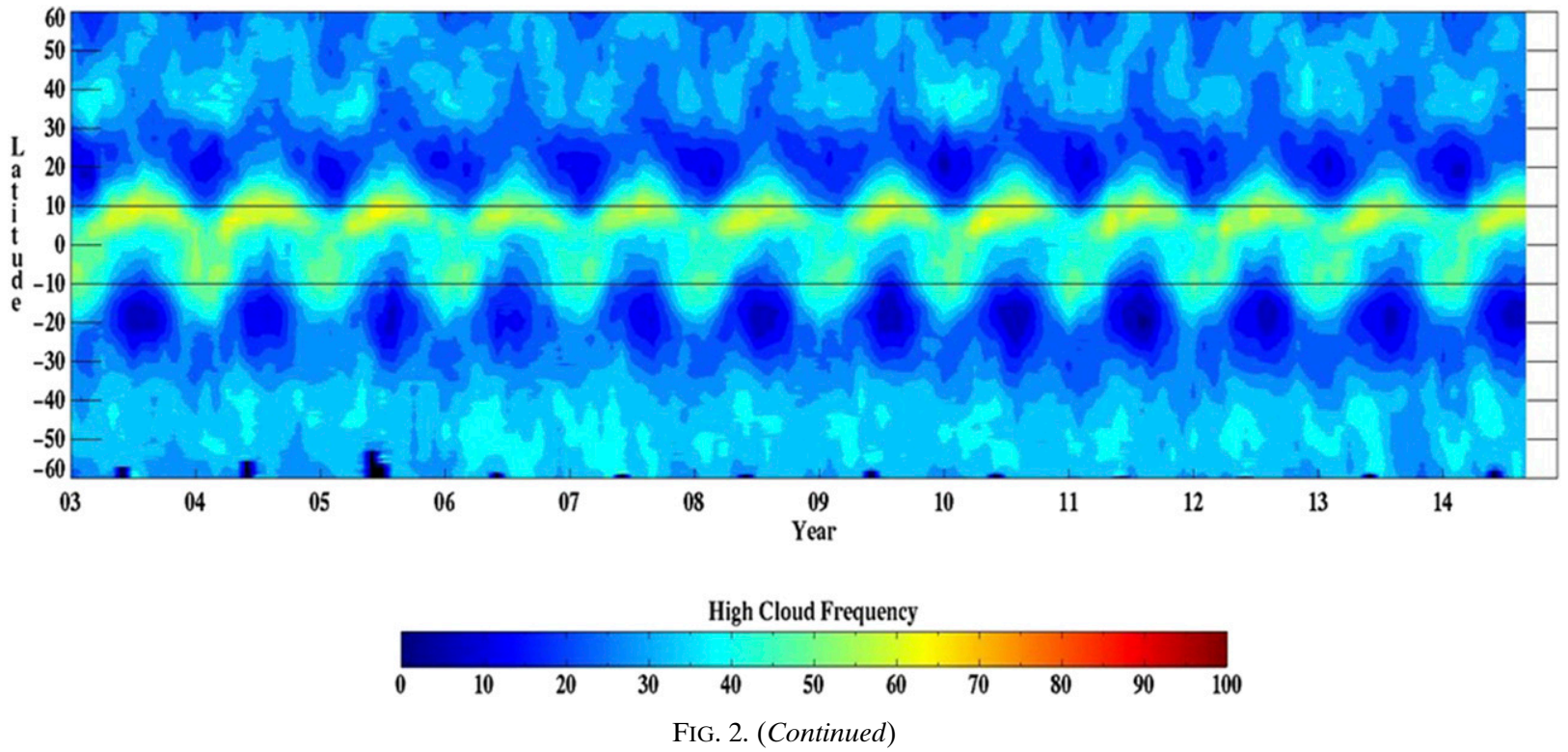

to be no obvious seasonal or other periodicities in the differences, concurring with Fig. 1 that showed similarities in HCF patterns but with different magnitudes.

Hemispheric high-cloud differences in both MODIS and HIRS (Fig. 3) agree that midyear the Northern Hemisphere has about $15 \%$ more high clouds than the Southern Hemisphere; 6 months later this reverses, with the Southern Hemisphere having about $10 \%$ more. This can also be seen in Figs. 2a and $2 \mathrm{~b}$ where differences are largest from latitudes centered on $10^{\circ} \mathrm{N}$ and $10^{\circ} \mathrm{S}$, where the maxima in the $\mathrm{NH}$ show higher values than the maxima in the SH. The peaks in the imbalance of HCFs between the hemispheres occur in August/September and January/February when the sea surface temperatures are at their maxima in the $\mathrm{NH}$ and $\mathrm{SH}$, respectively (Riehl and Simpson 1979). In most years, positive $\mathrm{NH}-\mathrm{SH}$ differences are found in 7 months of the year and negative differences in 5 months. This asymmetry is perhaps related to planetary energy balance where a warmer $\mathrm{NH}$, resulting in higher values of clear-sky outgoing longwave radiation (OLR), is balanced by higher and colder clouds (Stephens and L'Ecuyer 2015). This is consistent with Mace et al. (2009), who reported CloudSat/CALIPSO cloud heights higher in the NH by more than $1 \mathrm{~km}$ over those of the $\mathrm{SH}$.

Year-to-year HCF changes for all 12 months were averaged to produce maps of mean changes over the time period of the study. Frequency differences from 
(c) Hovmoller Diagram of HIRS-MODIS Night High Cloud Frequency Difference (\%)
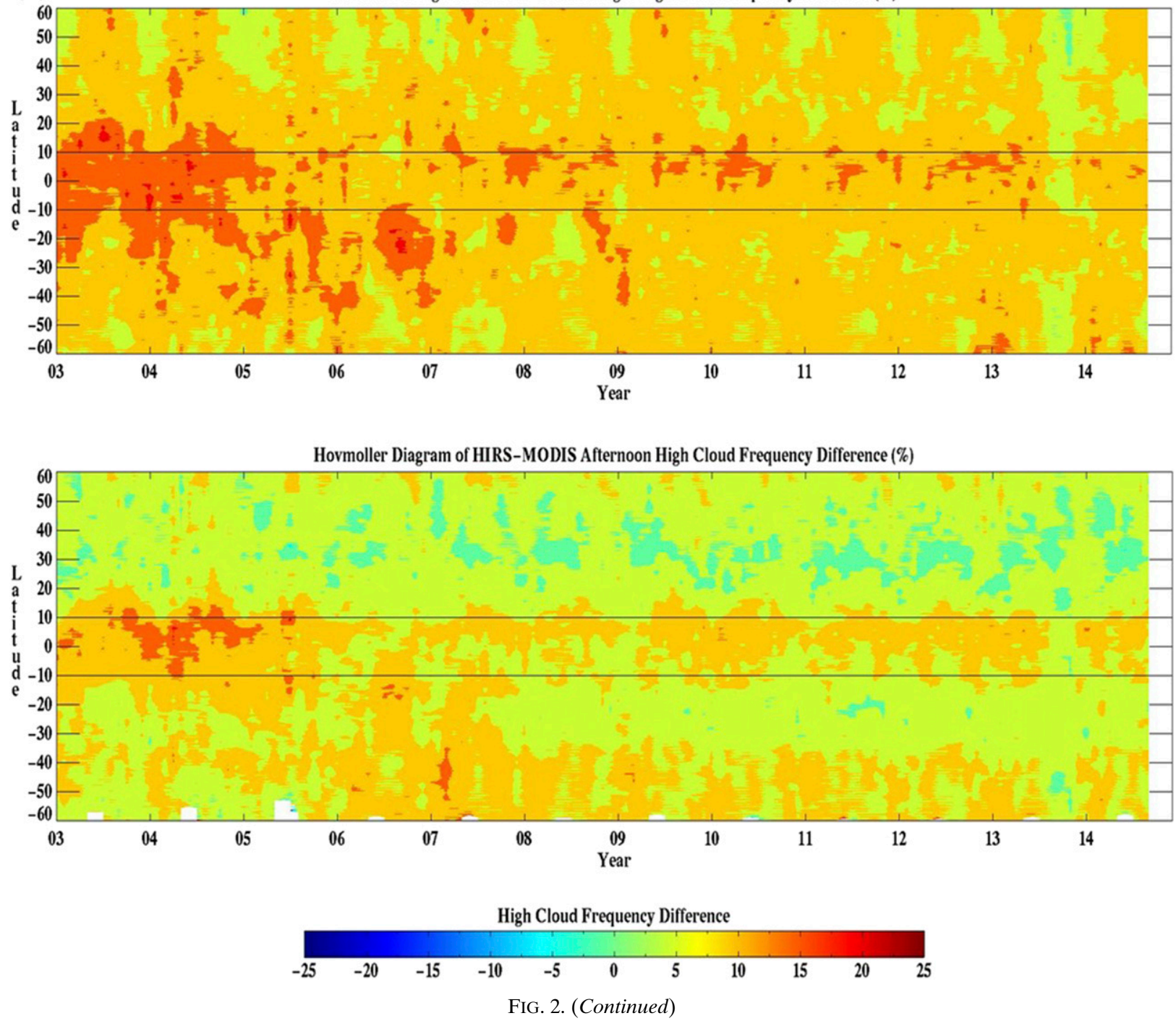

the 12 months were aggregated separately over the years 2003-13 and then averages were taken over all months to infer mean changes. Spatial resolution is $1^{\circ}$. In late August 2005 the operational sensor changed when NOAA-16 was replaced by NOAA-18; thus the 1 yr changes between September 2004 and September 2005 through to August 2005 and August 2006 were omitted from the average. And again in early June $2009, N O A A-18$ was replaced by $N O A A-19$ so the $1-\mathrm{yr}$ monthly differences involving June 2009-May 2010 were omitted from the average. The same monthly differences were also eliminated in the MODIS average to keep temporal coverage the same. Figures $4 a$ and $4 \mathrm{~b}$ show the global distribution of changes in $1^{\circ}$ latitude $\times 1^{\circ}$ longitude bins detected by HIRS and MODIS respectively; many large-scale patterns are similar but the strength of the changes can differ (e.g., HIRS sees more high-cloud decrease in the tropical oceans and MODIS sees more increase over northern South America). On the other hand, smaller-scale changes in both maps take on a rather random appearance, for example, in the Southern Ocean. Although there is some geographical coherence in the mean changes, the large year-to-year variability in the $1^{\circ}$ bins overwhelms any signal of cloud trends, with perhaps the exception of the ENSO cycle (few if any statistically significant trends are found).

HIRS same-sensor year-to-year HCF changes for each month from $60^{\circ} \mathrm{N}$ to $60^{\circ} \mathrm{S}$ were averaged (again omitting those months when replacement of the operational sensor affected the 1-yr-change determinations) 


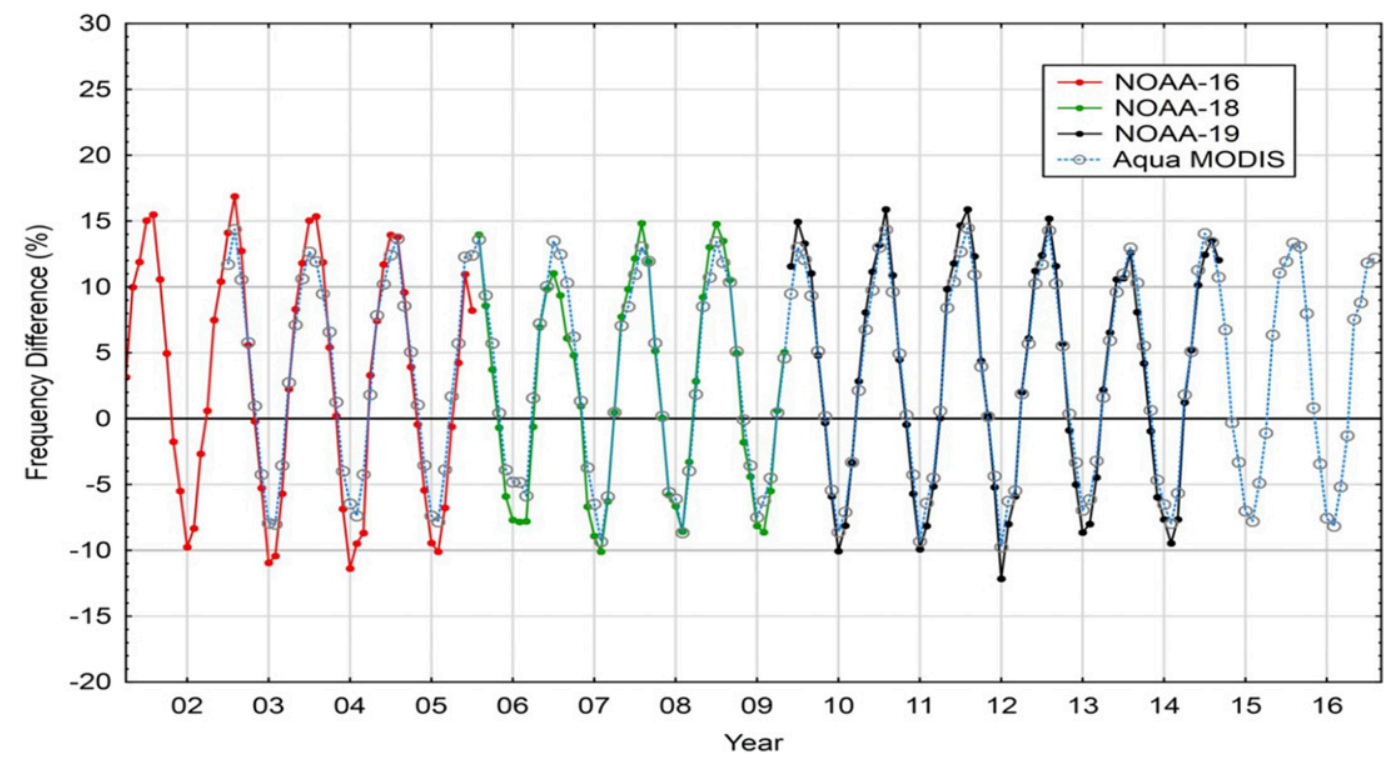

FIG. 3. Hemispheric difference (NH minus SH) in high-cloud detection for Aqua MODIS 2001-16 and NOAA-16, NOAA-18, and NOAA-19 HIRS 2003-14.

and the mean and root-mean-square (RMS) for each month in the years 2003-13 is shown in Fig. 5. HIRS mean monthly changes are larger in an absolute sense than those of MODIS; mean absolute monthly changes for HIRS are $-0.2 \%$ (with scatter about those means from $15.5 \%$ to $18.4 \%$ ) compared to $+0.1 \%$ for MODIS (with scatter about those means ranging from $12.9 \%$ to $16.7 \%$ ). Clearly there is considerable variability in the monthly means from year to year. HIRS and MODIS values in Fig. 5 are fairly consistent in sign of HCF change and relative magnitudes of RMS scatter from January through May. However, HIRS is very consistent in showing negative HCF changes from August through November while MODIS values are mostly weakly positive. Both datasets show lowest scatter in the month of August and highest values in February-April.

The associated latitudinal (zonal) distribution of the changes for night as well as day are plotted in Fig. 6. The zone-to-zone mean $\mathrm{HCF}$ changes are fairly smooth. Changes in the tropics differ; MODIS day and night sees a modest increase from $20^{\circ} \mathrm{S}$ to $5^{\circ} \mathrm{N}$ while HIRS at night sees a modest decrease, and HIRS during the day agrees with MODIS from $20^{\circ} \mathrm{S}$ to $10^{\circ} \mathrm{S}$ and then aligns with HIRS at night from $5^{\circ} \mathrm{S}$ to $5^{\circ} \mathrm{N}$. It is interesting to note that Aqua MODIS night and day latitudinal distributions are very similar as the Aqua equator crossing times are carefully controlled. For HIRS, the use of three instruments in the 11 years and the less rigid crossing times lead to some night and day differences. While the global patterns through the hemispheres are similar, inferring the mean changes is difficult due to sensitivity to FOV sizes and cloud detection thresholds.

\section{Summary}

High-cloud frequencies calculated from HIRS and MODIS radiance data have been compared for the years 2003-13. Seasonal cycles of high-cloud detection are in sync but the frequency of detection by HIRS is $10 \%$ higher than that of MODIS at night, somewhat less during afternoon. These differences are caused primarily by cloud detection threshold differences between the two. Seasonal and hemispheric patterns are quite similar; HIRS and MODIS NH-SH seasonal HCF differences agree to within $2 \%$ since 2002 . $\mathrm{NH}$ and $\mathrm{SH}$ seasonal maxima of HCFs are out of phase as expected, but $\mathrm{NH}$ maximum values are about $5 \%$ larger than those of the SH. This imbalance has been noted by others and implies that more high clouds balance the warmer surface in the NH in terms of OLR. Inferring trends is sensitive to FOV sizes and cloud detection thresholds. Regional and zonal mean changes in cloud frequencies over the study period were calculated for each dataset and compared. Major regional features compared well but showed varying strengths. Smaller changes were more random in nature. Zonal means displayed coherent positive and negative changes over time in the $\mathrm{NH}$, but small and perhaps random changes were seen in the SH where HIRS indicated fewer high clouds over time but MODIS showed 

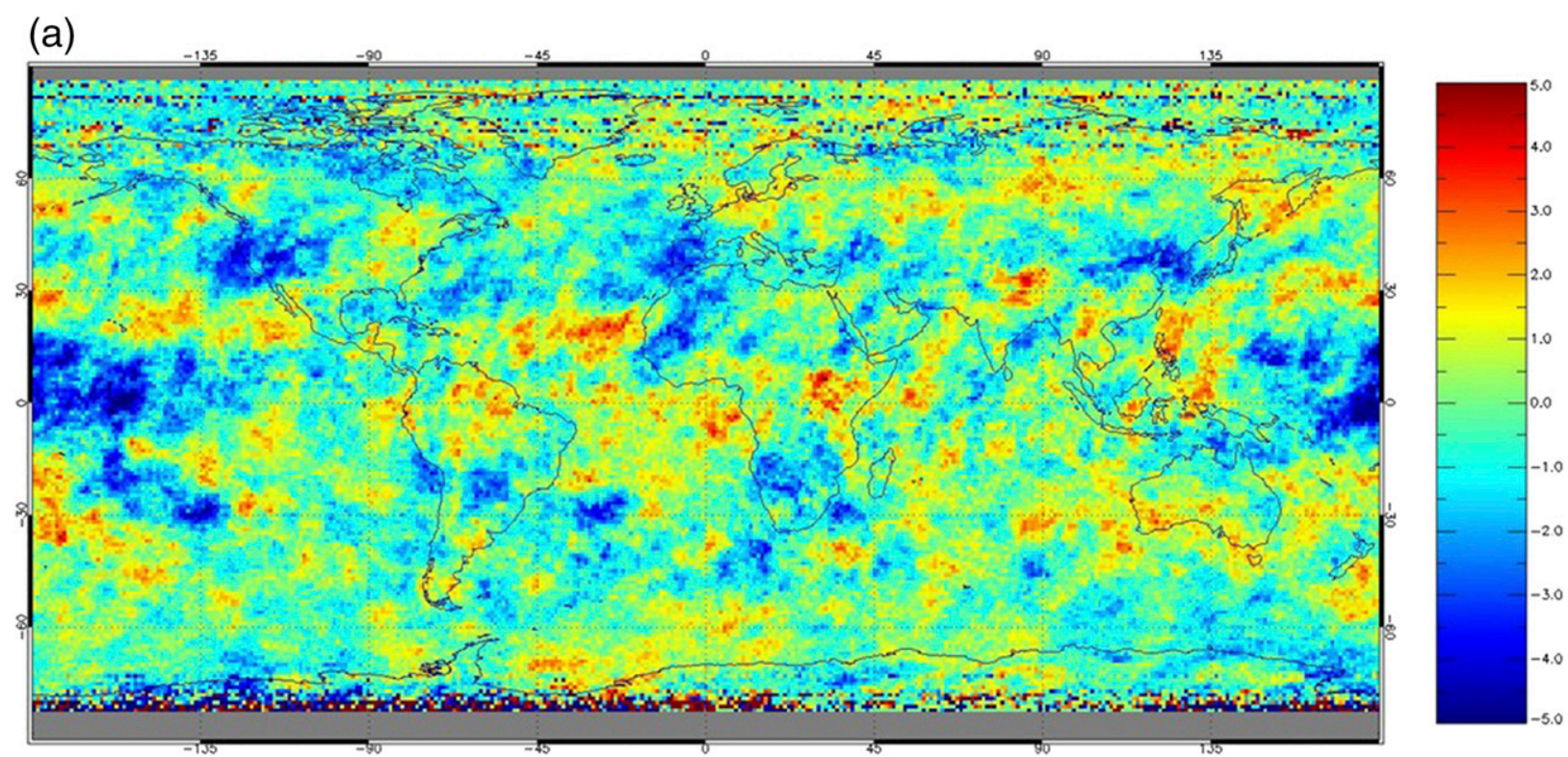

(b)

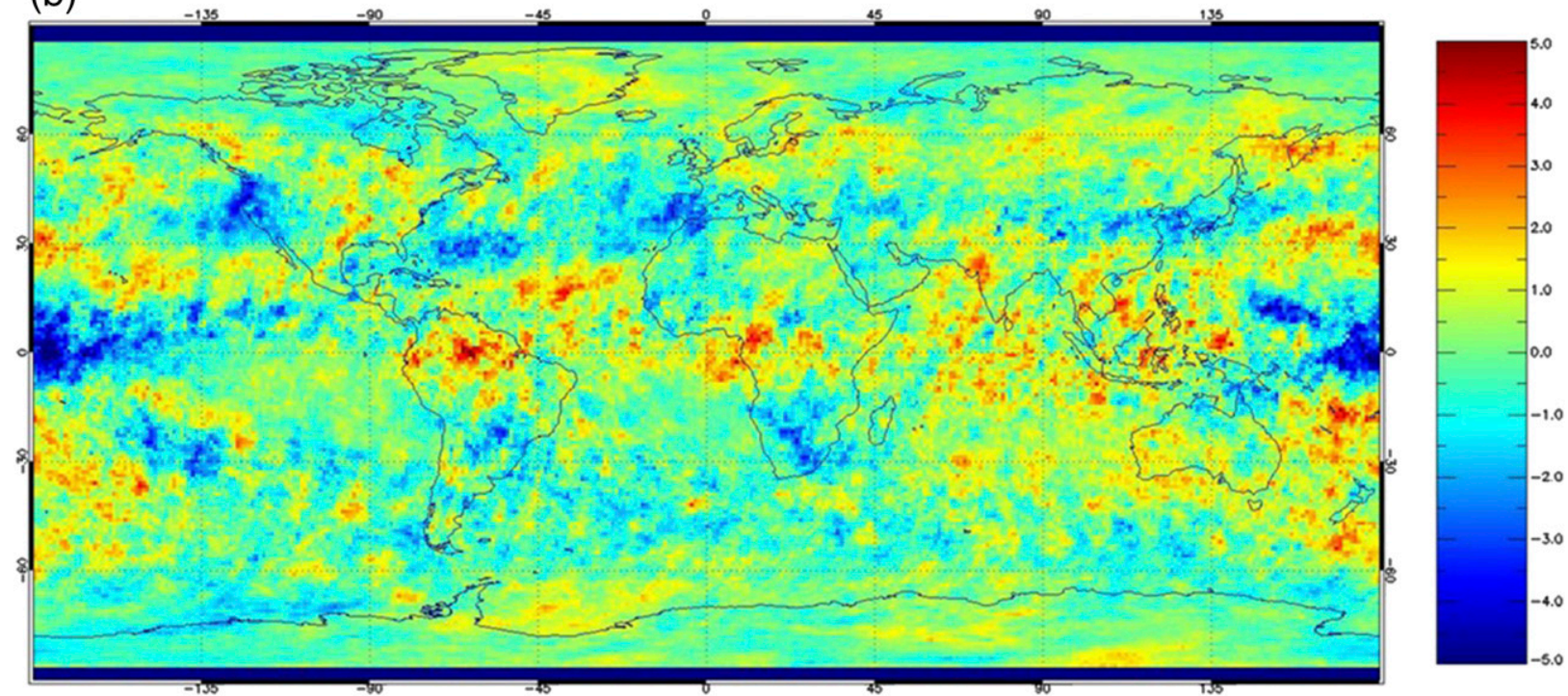

FIG. 4. (a) HIRS mean nighttime change in the frequency of high-cloud detection from 2003 to 2013 . Spatial resolution is $1^{\circ}$. Data from the HIRS sensors on NOAA-16, NOAA-18, and NOAA-19 are included. Same sensor detection of HCF differences for the same month from one year to the next were computed separately for all 12 months and then aggregated over the years $2003-13$; averages were taken over all months to infer mean changes. (b) Aqua MODIS descending-node (nighttime from $60^{\circ} \mathrm{S}$ to $60^{\circ} \mathrm{N}$ ) $\mathrm{mean}$ change in the frequency of high-cloud detection from 2003 to 2013. The same months were used as in the HIRS data in (a). Spatial resolution is $1^{\circ}$.

more. Mean monthly HCF changes showed similar patterns through the year with individual monthly values ranging between $-0.5 \%$ and $+0.2 \%$ for HIRS and between $-0.1 \%$ and $+0.3 \%$ for MODIS. Means of monthly RMS values were $17.3 \%$ and $15.0 \%$ for HIRS and MODIS, respectively. Thus, the natural variability in high cloud cover overwhelmed any trends that might be present due to the short time period sampled, input data uncertainties, and differences in the HIRS and MODIS treatment of the data.

The major conclusion offered in this paper is that the HIRS and MODIS HCF records complement each other. This gives confidence that the MODIS-era HIRS cloud determinations can be a bridge to the previous $20+$ years of HIRS data, that go back to 1978, and that the combined HIRS and MODIS cloud determinations will span over 40 years in a coherent manner. The results 


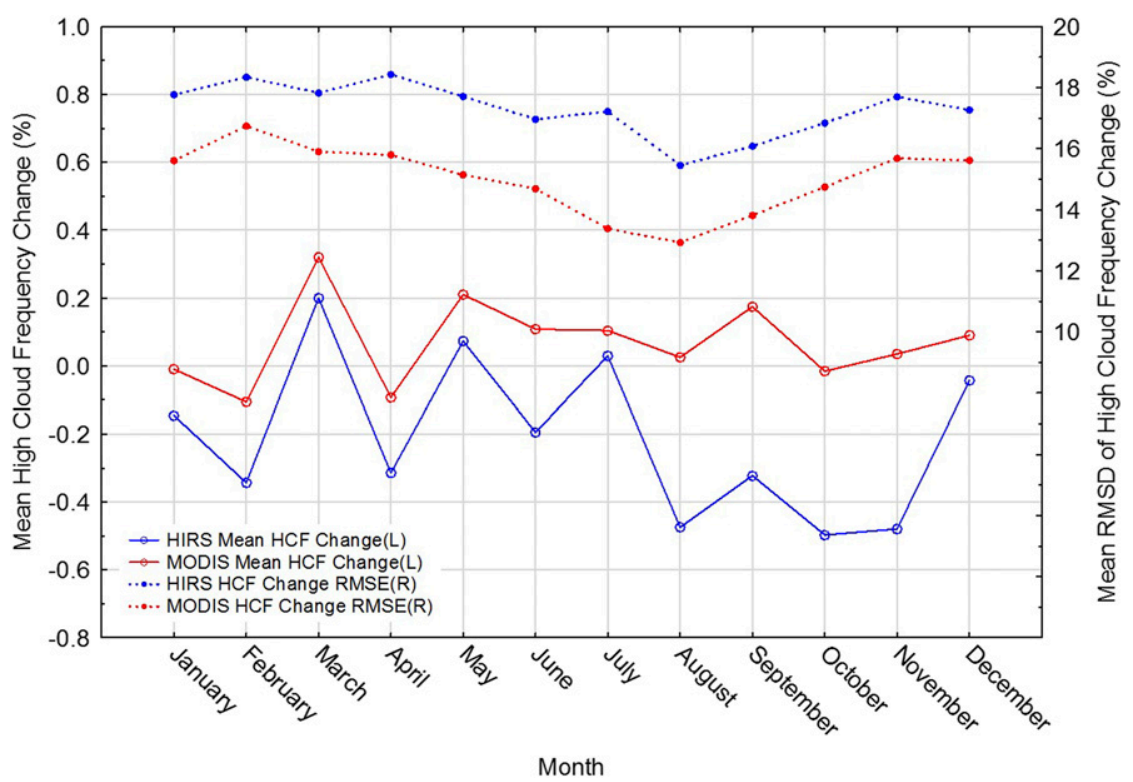

FIG. 5. HIRS (blue) and MODIS (red) mean (solid) and scatter (dotted) of nighttime year-to-year high-cloud frequency changes by month from $60^{\circ} \mathrm{S}$ to $60^{\circ} \mathrm{N}$ during $2003-13$.

from reprocessing of that longer HIRS record will be the subject of a future paper.

Acknowledgments. The authors are thankful for the NOAA and NASA support that has allowed us to pursue these HIRS and MODIS cloud studies (NOAA Contract NA15NES4320001 and NASA Contract NNX14AN48G).
In addition, we thank our colleagues at the National Centers for Environmental Information (NCEI) for establishing the HIRS dataset for broader user access. The PATMOS-x data were graciously provided by Dr. Andy Heidinger. We also thank Dr. Geoff Cureton who facilitated the comparisons between MODIS and HIRS cloud products.

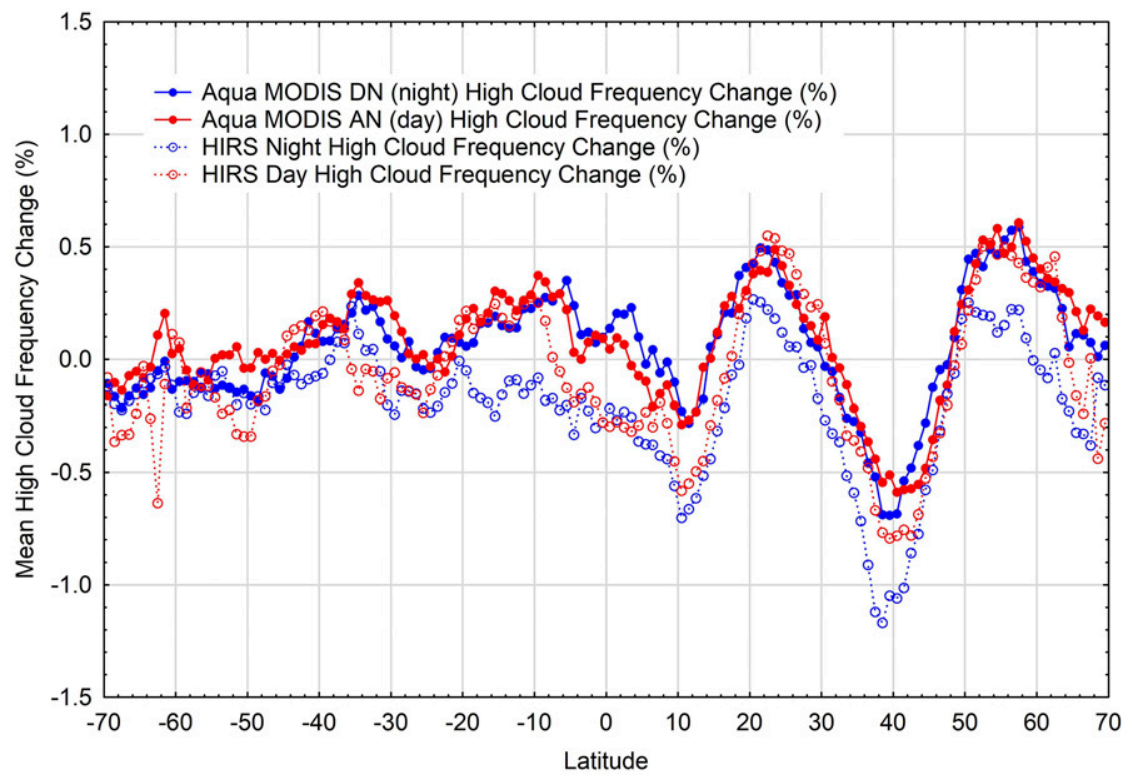

FIG. 6. HIRS (dotted) and MODIS (solid) zonal means of changes in annual frequency of high-cloud detection from 2003 to 2013 calculated for day (red) and night (blue). 


\section{REFERENCES}

Ackerman, S. A., K. I. Strabala, W. P. Menzel, R. A. Frey, C. C. Moeller, and L. E. Gumley, 1998: Discriminating clear sky from clouds with MODIS. J. Geophys. Res., 103, 32141-32 157, https://doi.org/10.1029/1998JD200032.

Baum, B. A., W. P. Menzel, R. A. Frey, D. C. Tobin, R. E. Holz, S. A. Ackerman, A. K. Heidinger, and P. Yang, 2012: MODIS cloud top property refinements for Collection 6. J. Appl. Meteor. Climatol., 51, 1145-1163, https://doi.org/10.1175/ JAMC-D-11-0203.1.

Chen, R., C. Cao, and W. P. Menzel, 2013: Intersatellite calibration of NOAA HIRS $\mathrm{CO}_{2}$ channels for climate studies. J. Geophys. Res. Atmos., 118, 5190-5203, https://doi.org/ 10.1002/jgrd.50447.

Chen, T., W. B. Rossow, and Y. Zhang, 2000: Radiative effects of cloud-type variations. J. Climate, 13, 264-286, https://doi.org/ 10.1175/1520-0442(2000)013<0264:REOCTV > 2.0.CO;2.

Eastman, R., and S. G. Warren, 2013: A 39-yr survey of cloud changes from land stations worldwide 1971-2009: Long-term trends, relation to aerosols, and expansion of the tropical belt. J. Climate, 26, 1286-1303, https://doi.org/10.1175/JCLI-D12-00280.1.

Evan, A. T., A. K. Heidinger, and D. J. Vimont, 2007: Arguments against a physical long-term trend in global ISCCP cloud amounts. Geophys. Res. Lett., 34, L04701, https://doi.org/ 10.1029/2006GL028083.

Foster, M. J., and A. K. Heidinger, 2013: PATMOS-x: Results from a diurnally corrected 30-yr satellite cloud climatology. J. Climate, 26, 414-425, https://doi.org/10.1175/JCLI-D11-00666.1.

Hartmann, D., M. Ockert-Bell, and M. Michelsen, 1992: The effect of cloud type on Earth's energy balance: Global analysis. J. Climate, 5, 1281-1304, https://doi.org/10.1175/ 1520-0442(1992)005<1281:TEOCTO>2.0.CO;2.

Heidinger, A. K., A. T. Evan, M. J. Foster, and A. Walther, 2012: A naive Bayesian cloud-detection scheme derived from CALIPSO and applied within PATMOS-x. J. Appl. Meteor. Climatol., 51, 1129-1144, https://doi.org/10.1175/JAMC-D-11-02.1.

— M. J. Foster, A. Walther, and X. Zhao, 2014: The Pathfinder Atmospheres-Extended AVHRR climate dataset. Bull. Amer. Meteor. Soc., 95, 909-922, https://doi.org/10.1175/ BAMS-D-12-00246.1.

Kalnay, E., and Coauthors, 1996: The NCEP/NCAR 40-Year Reanalysis Project. Bull. Amer. Meteor. Soc., 77, 437-472, https:// doi.org/10.1175/1520-0477(1996)077<0437:TNYRP>2.0.CO;2.

Kanamitsu, M., and Coauthors, 1991: Recent changes implemented into the global forecast system at NMC. Wea. Forecasting, 6, 425-435, https://doi.org/10.1175/1520-0434(1991) $006<0425:$ RCIITG $>2.0 . \mathrm{CO} ; 2$.

Kolat, U., 2010: Re-evaluation of HIRS detection of high clouds. Master's thesis, Dept. of Atmospheric and Oceanic Sciences, University of Wisconsin-Madison, $47 \mathrm{pp}$.

Mace, G. G., Q. Zhang, M. Vaughan, R. Marchand, G. Stephens, C. Trepte, and D. Winker, 2009: A description of hydrometeor layer occurrence statistics derived from the first year of merged CloudSat and CALIPSO data. J. Geophys. Res., 114, D00A26, https://doi.org/10.1029/2007JD009755

Menzel, W. P., D. P. Wylie, and K. I. Strabala, 1992: Seasonal and diurnal changes in cirrus clouds as seen in four years of observations with the VAS. J. Appl. Meteor., 31, 370-385, https:// doi.org/10.1175/1520-0450(1992)031<0370:SADCIC > 2.0.CO;2. , and Coauthors, 2008: MODIS global cloud-top pressure and amount estimation: Algorithm description and results. J. Appl. Meteor. Climatol., 47, 1175-1198, https://doi.org/10.1175/ 2007JAMC1705.1.

— - R. A. Frey, E. E. Borbas, B. A. Baum, G. Cureton, and N. Bearson, 2016: Reprocessing of HIRS satellite measurements from 1980 to 2015: Development toward a consistent decadal cloud record. J. Appl. Meteor. Climatol., 55 , 2397-2410, https://doi.org/10.1175/JAMC-D-16-0129.1.

Nagle, F. W., and R. E. Holz, 2009: Computationally efficient methods of collocating satellite, aircraft, and ground observations. J. Atmos. Oceanic Technol., 26, 1585-1595, https:// doi.org/10.1175/2008JTECHA1189.1.

Riehl, H., and J. Simpson, 1979: The heat balance of the equatorial trough zone revisited. Contrib. Atmos. Phys., 52, 287-305.

Rossow, W. B., and R. A. Schiffer, 1991: ISCCP cloud data products. Bull. Amer. Meteor. Soc., 72, 2-20, https://doi.org/10.1175/ 1520-0477(1991)072<0002:ICDP >2.0.CO;2.

Salomonson, V. V., W. L. Barnes, P. W. Maymon, H. E. Montgomery, and H. Ostrow, 1989: MODIS: Advanced facility instrument for studies of the earth as a system. IEEE Trans. Geosci. Remote Sens., 27, 145-153, https://doi.org/ 10.1109/36.20292.

Schiffer, R. A., and W. B. Rossow, 1983: The International Satellite Cloud Climatology Project (ISCCP): The first project of the World Climate Research Programme. Bull. Amer. Meteor. Soc., 64, 779-784, https://doi.org/10.1175/1520-0477-64.7.779.

Smith, W. L., H. L. Huang, and J. A. Jenney, 1996: An advanced sounder cloud contamination study. J. Appl. Meteor., 35, 1249-1255, https://doi.org/10.1175/1520-0450(1996) 035<1249:AASCCS > 2.0.CO;2.

Stephens, G., and T. L'Ecuyer, 2015: The Earth's energy balance. Atmos. Res., 166, 195-203, https://doi.org/10.1016/ j.atmosres.2015.06.024.

Wylie, D., and P. Wang, 1997: Comparison of cloud frequency from the high-resolution infrared radiometer sounder and the Stratospheric Aerosol and Gas Experiment II. J. Geophys. Res., 102, 29 893-29 900, https://doi.org/10.1029/97JD02360.

_ , and W. P. Menzel, 1999: Eight years of high cloud statistics using HIRS. J. Climate, 12, 170-184, https://doi.org/10.1175/ 1520-0442-12.1.170.

- D. L. Jackson, W. P. Menzel, and J. J. Bates, 2005: Trends in global cloud cover in two decades of HIRS observations. J. Climate, 18, 3021-3031, https://doi.org/10.1175/JCLI3461.1.

Zhou, C., M. Zelinka, and S. Klein, 2016: Impact of decadal cloud variations on the Earth's energy balance. Nat. Geosci., 9 , 871-874, https://doi.org/10.1038/ngeo2828. 